2013

\title{
Metastable Nanostructured Metallized Fluoropolymer Composites for Energetics
}

\author{
Hannah A. Miller \\ United States Air Force Academy \\ Bradley S. Kusel \\ United States Air Force Academy \\ Seth T. Danielson \\ United States Air Force Academy \\ James W. Neat \\ United States Air Force Academy \\ Eryn K. Avjian \\ United States Air Force Academy
}

See next page for additional authors

Follow this and additional works at: https://engagedscholarship.csuohio.edu/scichem_facpub

Part of the Materials Chemistry Commons, and the Physical Chemistry Commons

How does access to this work benefit you? Let us know!

\section{Recommended Citation}

Miller, H. A.; Kusel, B. S.; Danielson, S. T.; Neat, J. W.; Avjian, E. K.; Pierson, S. N.; Budy, S. M.; Ball, D. W.; lacono, S. T.; Kettwich, S. C. Metastable nanostructured metallized fluoropolymer composites for energetics. J. Mater. Chem. A 2013, 1, 7050-7058.

This Article is brought to you for free and open access by the Chemistry Department at EngagedScholarship@CSU. It has been accepted for inclusion in Chemistry Faculty Publications by an authorized administrator of EngagedScholarship@CSU. For more information, please contact library.es@csuohio.edu. 


\section{Authors}

Hannah A. Miller, Bradley S. Kusel, Seth T. Danielson, James W. Neat, Eryn K. Avjian, Scott N. Pierson, Stephen M. Budy, David W. Ball, Scott T. Iacono, and Sharon C. Kettwich 


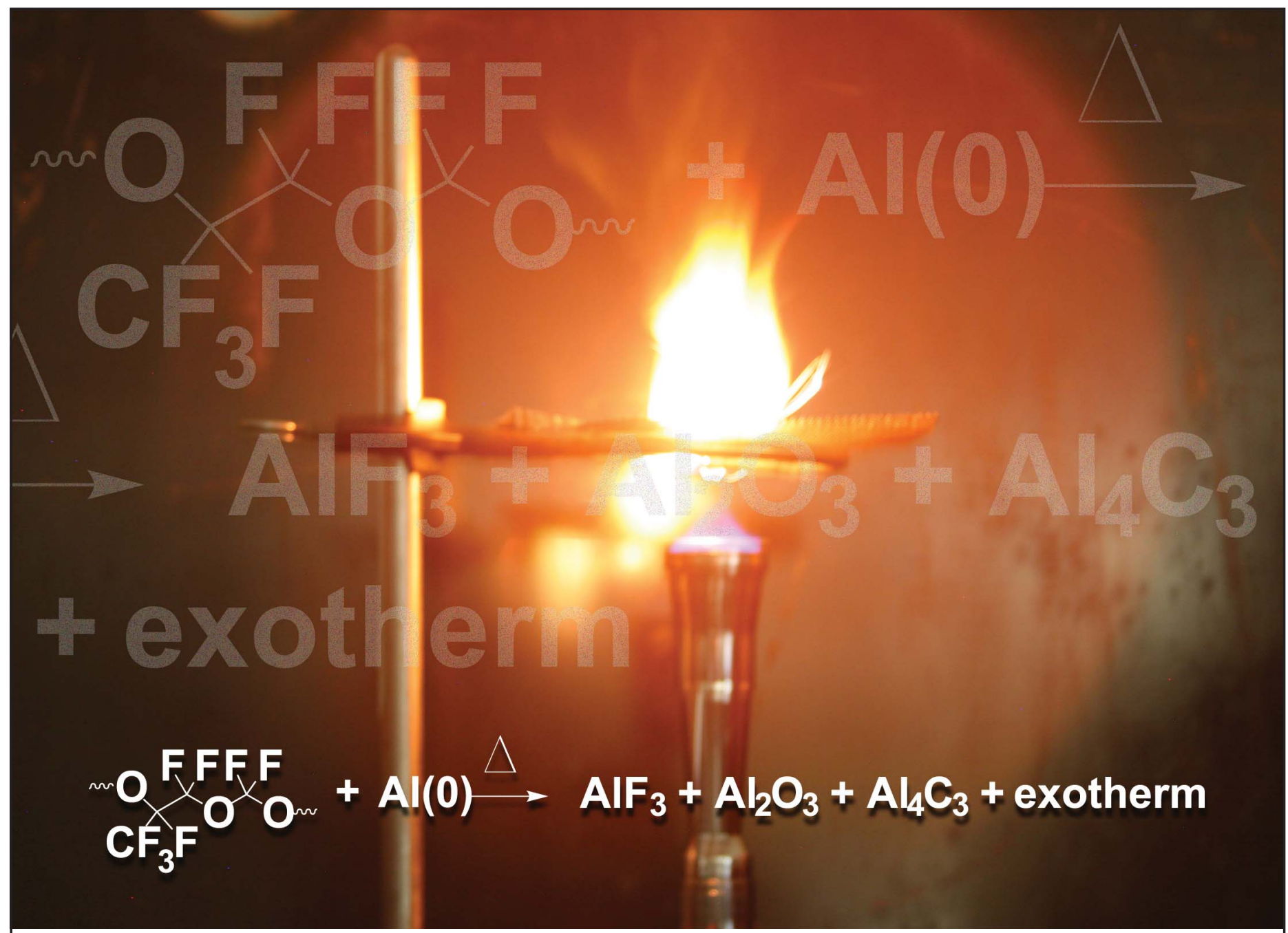

Showcasing research on metastable composites from the laboratory of Prof. Scott lacono and Dr. Sharon Kettwich at the Chemistry Research Center, Department of Chemistry, US Air Force Academy.

Title: Metastable nanostructured metallized fluoropolymer composites for energetics

Metastable composites were prepared from a fluoropolymer-coated nano-aluminum blended formulation entrained in an epoxy matrix. This composition produced a moldable/post-machinable composite that undergoes thermally activated metal-mediated oxidation. The simplistic, scalable design can warrant consideration for a new class of engineered metal-based fluoropolymer pyrolant composite systems.

\section{As featured in:}

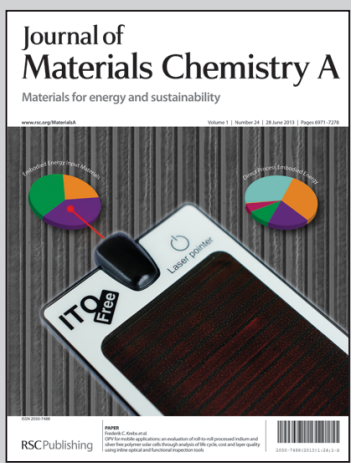

See S. T. lacono et al., J. Mater. Chem. A, 2013, 1, 7050. 
Cite this: J. Mater. Chem A, 2013, 1 7050

Received 22nd April 2013

Accepted 26th April 2013

DOI: $10.1039 / c 3 t a 11603 d$

www.rsc.org/MaterialsA
View Article Online

View Journal | View Issue

\title{
Metastable nanostructured metallized fluoropolymer composites for energetics
}

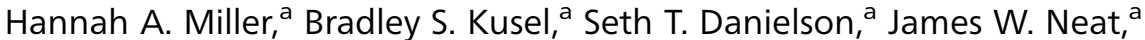 \\ Eryn K. Avjian, ${ }^{a}$ Scott N. Pierson, ${ }^{a}$ Stephen M. Budy, ${ }^{\text {b }}$ David W. Ball, ${ }^{c}$ Scott T. Iacono*a \\ and Sharon C. Kettwich*a
}

\begin{abstract}
Fluoropolymers have long served as potent oxidizers for metal-based pyrolant designs for the preparation of energetic materials. Commercial perfluoropolyethers (PFPEs), specifically known as Fomblins ${ }^{\circledR}$, are wellknown to undergo accelerated thermal degradation in the presence of native metals and Lewis acids producing energetically favorable metal fluoride species. This study employs the use of PFPEs to coat nano-aluminum ( $\mathrm{n}-\mathrm{Al}$ ) and under optimized stoichiometric formulations, harness optimized energy output. The PFPEs serve as ideal oxidizers of $n$-Al because they are non-volatile, viscous liquids that coat the particles thereby maximizing surface interactions. The $n-A l / P F P E$ blended combination is required to interface with an epoxy-based matrix in order to engineer a moldable/machinable, structurally viable epoxy composite without compromising bulk thermal/mechanical properties. Computational modeling/ simulation supported by thermal experimental studies showed that the n-Al/PFPE blended epoxy composites produced an energetic material that undergoes latent thermal metal-mediated oxidation. Details of the work include the operationally simple, scalable synthetic preparation, thermal properties from DSC/TGA, and SEM/TEM of these energetic metallized nanocomposite systems. Post-burn analysis using powder XRD of this pyrolant system confirms the presence of the predominating exothermic metal-mediated oxidized $\mathrm{AlF}_{3}$ species in addition to the production of $\mathrm{Al}_{2} \mathrm{O}_{3}$ and $\mathrm{Al}_{4} \mathrm{C}_{3}$ during the deflagration reaction. Details of this first epoxy-based energetic nanocomposite entrained with a thermally reactive formulation of PFPE coated n-Al particles are presented herein.
\end{abstract}

\section{Introduction}

Energetic materials consisting of a metal fuel and fluoropolymer oxidizer are increasingly prevalent constituents in energetic materials development due to their high energy densities. ${ }^{1}$ The enthalpy of formation of the metal-halogen bond is the driving force behind oxidation of the metal and results in the exothermic release of energy. Out of all the halogen-based fuels, fluorocarbons have been shown to outperform fluorine-free systems. ${ }^{2}$ Metal-fluorine bond formation is thermodynamically favored to any combination of the starting metal, thus reactants are energetically obligated to rearrange into decomposition products. Poly(chlorotrifluoroethylene) (PCTFE or Kel-F) was the first fluorocarbon-based polymer used to oxidize magnesium metal in pyrotechnics in $1956 .^{3}$ Since then, numerous metal-fluoropolymer systems have been developed for various energetic applications including magnesium/

\footnotetext{
aDepartment of Chemistry and Chemistry Research Center, United States Air Force Academy, 2355 Fairchild Drive, Suite 2N225 USAF Academy, CO 80840, USA. E-mail: scott.iacono@usafa.edu; sharon.kettwich@usafa.edu

${ }^{b}$ Department of Materials Science and Engineering, University of Arizona, 1235 East James E. Rogers Way, Tucson, AZ 85721, USA

'Department of Chemistry, Cleveland State University, Cleveland, OH 44115, USA
}

poly(tetrafluoroethylene) (PTFE or Teflon $\left.{ }^{\circledR}\right) /$ Kel-F based infrared flare compositions and the well-studied pyrolant magnesium/Teflon/vinylidenefluoride-hexafluoroisopropene copolymer (Viton ${ }^{\circledR}$ ), otherwise known as MTV. ${ }^{2,4,5}$ Lithium, titanium, zirconium, and aluminum are some notable representative examples of the fuels that have been used in place of magnesium when considering engineering metal-fluorocarbon materials. ${ }^{6-8}$ Integration of reactive systems with a structural material is of particular interest in order to make useful, reliable, and safe energetic materials such as reactive foils for micro-welding, structural propellants, high explosives, and thermites. ${ }^{9}$ As a recent example, Pantoya et al. have extensively investigated micro- and nanometer-sized aluminum (denoted $\mu-\mathrm{Al}$ and $\mathrm{n}-\mathrm{Al}$ ) energetic composites made from a variety of fluoropolymers including Teflon ${ }^{\circledR} .^{\mathbf{8 , 1 0 , 1 1}}$ The increased specific surface area when going from $\mu$-Al to $\mathrm{n}$-Al powders increases reaction rates by several orders of magnitude, lowers ignition times and increases energy output of energetic materials. ${ }^{12,13}$ However, the increased surface area makes the particles more prone to aggregation in order to minimize their free energy. ${ }^{14}$ In order to mitigate this, Crouse et al. have functionalized n-Al with oleic acid $^{15}$ and acrylic monomers ${ }^{13}$ (used to further produce energetic nanocomposites ${ }^{\mathbf{1 6}}$ ) in order to minimize 
particle aggregation. Furthermore, the use of the electrospinning technique was used to prepare non-woven, highsurface area energetic textiles with well-dispersed n-Al particles in a nanofiber matrix. ${ }^{\mathbf{1 7}}$

Secondary coatings, such as functionalization or additional passivation layers have been shown to provide further protection against increased oxidation thereby extending the shelf life of the core metal. ${ }^{18-20}$ Perfluoropolyethers (PFPEs) are low molecular weight fluorinated oligomers that have been used in the aerospace, automotive, and machining industries because they are practically non-volatile and exhibit a nearly temperature independent viscosity. ${ }^{21}$ While PFPEs are stable in an inert atmosphere up to $410{ }^{\circ} \mathrm{C}$ and to approximately $316^{\circ} \mathrm{C}$ in an oxygen-rich environment, they are catalytically decomposed by metals and Lewis acids at lower temperatures..$^{22-24} A b$ initio calculations of perfluorodiethylether $\left(\left(\mathrm{CF}_{3} \mathrm{CF}_{2}\right)_{2} \mathrm{O}\right)$ as model systems to PFPEs concluded that protonation via Lewis acids at all sites (fluorine and oxygen atoms) is energetically favorable. ${ }^{25}$ Therefore, it is probable that decomposition is not totally due solely to acid-mediated reactions with the polyether oxygen as previously believed, but may also involve reaction with fluorine and the possible formation of $\mathrm{HF}$ as an excellent leaving group. $^{22,26}$ Thin films of the PFPE Fomblin Y 140/13 and magnesium powder have been made and analyzed using temperature programmed desorption (TPD) to study the interaction between the magnesium and the PFPE. ${ }^{27}$ It was found that the PFPE was involved in decomposition and desorption reactions as well as passivating the metal before it reached its melting temperature by forming magnesium-fluoride bonds. It can be postulated that energetic materials, such as binders, flares and torches, propellants, or explosives, can be designed to take advantage of the energy released upon intentional degradation of PFPEs.

In this work, we take advantage of the high enthalpy of formation of metal-fluorine bonds in order to create metalized fluorocarbon energetic materials. In an operationally simple approach (Scheme 1), we have engineered a structural metastable intermolecular composite (MIC) by: (1) coating n-Al particles with the PFPE Fomblin ${ }^{\circledR}$ which serves as an additional passivation layer to suppress further oxidation in air and (2) casting n-Al/PFPE blends into prefabricated epoxy molds. These new aluminized fluorinated epoxide nanocomposites are moldable/machinable and are stable in open-air. Herein, we report the synthetic details and complete characterization of the thermal behavior and surface properties of these energetic nanocomposites.

\section{Experimental section}

\section{Materials}

Diethylenetriamine (DETA, >60\%), bisphenol A diglycidyl ether (BADGE), and the perfluoropolyether (PFPE) (Fomblin ${ }^{\circledR}$ Y LVAC 25/6, avg mol wt $3300 \mathrm{~g} \mathrm{~mol}^{-1}$ ) were all purchased from SigmaAldrich and were used as received without any further purification. The nanometer-sized aluminum (n-Al) powder was obtained from the US Army Armament Research, Development, and Engineering Center (ARDEC) and has an average particle size distribution of $80 \mathrm{~nm}$, as determined by TEM by the supplier. The manufacturer found the aluminum to be $c a$. $70 \%$ active as determined by TGA analysis by measuring the mass gain due to oxidation.

\section{Characterization}

Differential scanning calorimetry (DSC) was performed on a TA Auto Q20 Instrument in a nitrogen environment. The nitrogen is from the head space on a liquid nitrogen tank that passes through Drierite before entering the sample chamber. Samples (ca. $5 \mathrm{mg}$ ) are sealed in aluminum hermetic pan with an empty sealed hermetic pan serving as the reference. Thermal transitions were reported on the third heating cycle. Samples are heated from $20{ }^{\circ} \mathrm{C}$ to $200{ }^{\circ} \mathrm{C}$ at a rate of $5{ }^{\circ} \mathrm{C} \mathrm{min}{ }^{-1}$ and then cooled down to $20^{\circ} \mathrm{C}$, twice. This heating ramp is repeated to a final temperature of $500{ }^{\circ} \mathrm{C}$.

Thermal gravimetric analysis (TGA) was performed on a TA Q500 instrument at a scan rate of $5{ }^{\circ} \mathrm{C} \mathrm{min}^{-1}$ in nitrogen. The nitrogen is taken from the head space on a liquid nitrogen tank that first passes through Drierite. Samples (5-10 mg) are measured with a platinum crucible and heated from room temperature to $900{ }^{\circ} \mathrm{C}$.

TA Universal Analysis 2000 graphical software is used to determine the onset $\left(T_{\mathrm{O}}\right)$ and maximum $\left(T_{\mathrm{M}}\right)$ temperatures of exothermic events as well as integrated enthalpies $(\Delta H)$. It is also used to determine glass transition $\left(T_{\mathrm{g}}\right)$ and decomposition temperatures $\left(T_{\mathrm{d}}\right)$, along with remaining mass balances (n-Al bal)/char yields (\%).

Scanning electron microscopy (SEM) images were acquired at the Advanced Materials Research Laboratories (AMRL) at Clemson University on a Hitachi SU-6600 Field Emission SEM with an Oxford Instruments X-Max Silicon Drift Detector (SDD). Images were collected using a $10 \mathrm{kV}$ accelerating voltage and a working distance of $\sim 10 \mathrm{~mm}$. The Deben Peltier cool stage was set to $-32{ }^{\circ} \mathrm{C}$ and stabilized at $-27^{\circ} \mathrm{C}$. Samples were frozen in $\mathrm{LN}_{2}$ prior to observation. To prepare samples for SEM
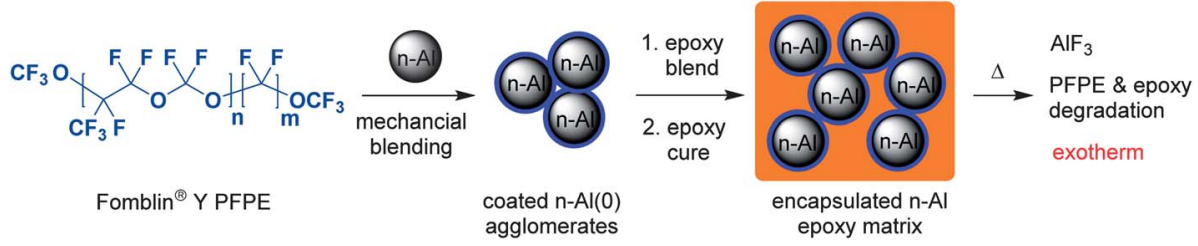

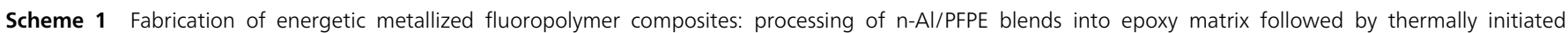
degradation. 
observation, the $\mathrm{n}-\mathrm{Al}$ powder and $\mathrm{n}-\mathrm{Al} / \mathrm{PFPE}$ blends were secured to aluminum base stubs using carbon tape, and the stubs were cooled over liquid $\mathrm{N}_{2}$. The composite samples were secured to the aluminum base stubs using a droplet of water, which instantly freezes and bonds the sample to the base stub. The pre-cooled stubs (with attached specimens) were loaded into the cool stage of the microscope, which was then set to a temperature of $-32{ }^{\circ} \mathrm{C}$. The stage actually operated at a temperature range of $-20{ }^{\circ} \mathrm{C}$ to $-10{ }^{\circ} \mathrm{C}$ and the microscope operated under a $0.225 \mathrm{mmHg}$ vacuum.

Transmission electron microscopy (TEM) micrographs were obtained from a Hitachi H-7600 Transmission Electron Microscope at the Clemson University Electron Microscope Facility. A $100 \mathrm{kV}$ accelerating voltage was used and the objective aperture was out. To prepare thin sections for TEM, the n-Al powder and the $\mathrm{n}-\mathrm{Al} / \mathrm{PFPE}$ blends were suspended in distilled water and a droplet was placed on a $3 \mathrm{~mm}$ copper 200-mesh grid with carbon formvar coating. Composite samples were sectioned using a Reichert-Jung Ultracut E microtome to a thickness of about 90-120 nm and placed on copper grids prior to analysis.

Powder X-ray diffraction (XRD) was performed on a PANalytical X'Pert Pro instrument. The X-ray source is a high intensity ceramic sealed tube $(3 \mathrm{~kW})$ with a wavelength of $1.5406 \AA(\mathrm{Cu} \mathrm{K})$. Measurements were taken on a zero diffraction background sample holder. The samples were continuously scanned in the range $20-1302 \theta$ with a $0.017^{\circ}$ step size and $10.16 \mathrm{~s}$ per step with a $2^{\circ}$ slit size. Data were collected using PANalytical X'Pert HighScore suite software and processed using Origin (version 6.1). Qualitative combustion experiments for XRD were performed by placing a small portion of the samples on a ceramic tile in a fume hood in air. They are ignited directly by the flame from a propane torch and the charred residue from the burn was used for XRD analysis.

\section{n-Al/PFPE blend preparation}

All blends are prepared in an MBraun Labmaster glovebox under nitrogen. Neat blends of 10, 20, 30, and $40 \mathrm{wt} \%$ of n-Al powder with PFPE are weighed directly into a glass screw cap vial and manually mixed with a spatula for $5 \mathrm{~min}$. The vials are then capped and the blends are then removed from the glove box for analysis and composite preparation.

\section{BADGE/TETA epoxy resin preparation}

Optimized epoxy resin formulations were produced by mixing BADGE (2.73 mL or $3.20 \mathrm{~g}, 9.40 \mathrm{mmol}, 80 \mathrm{wt} \%$ ) and DETA $(0.84 \mathrm{~mL}$ or $0.80 \mathrm{~g}, 7.75 \mathrm{mmol}, 20 \mathrm{wt} \%)$ in a glass vial and the neat mixture is vortexed for $1 \mathrm{~min}$ to ensure thorough mixing. The viscous liquid is then poured into a circular plastic mold (25 $\mathrm{mm}$ ID, $6 \mathrm{~mm}$ thickness) that is open on the top and bottom and the bottom is secured by Parafilm wrap. The plastic mold and Parafilm wrap is pre-treated with a lightly coated with Dow Corning 976V High Vacuum Grease Silicone in order to release the puck after curing. The sample is cured in a vacuum oven at $60{ }^{\circ} \mathrm{C}$ for $2.5 \mathrm{~h}$ or $16 \mathrm{~h}$ at room temperature on the bench top producing an optically transparent, rigid solid.

\section{PFPE/BADGE/TETA composite preparation}

BADGE/TETA formulation is prepared in the same manner as described above, but is allowed to partially cure on the bench top at room temperature for approximately $2 \mathrm{~h}$ before adding various loadings of PFPE $(5,10,15,20$ and $30 \mathrm{wt} \%)$. After addition of the PFPE, the entire mixture is stirred manually with a spatula for $1 \mathrm{~min}$ to ensure a homogenous distribution of the PFPE into the composite. The BADGE/TETA/PFPE mixture is then allowed to fully cure in open air at room temperature for 16-24 h producing a white, homogeneous, rigid solid.

\section{n-Al/PFPE/BADGE/TETA composite preparation}

BADGE/TETA formulation is prepared and partially cured in the same manner as previously described before adding various loadings of n-Al/PFPE blends (10, 20, 30 and $40 \mathrm{wt} \%$ Al loading) which equates to overall loadings of 1\% n-Al, 9\% PFPE, 90\% BADGE/TETA; 4\% n-Al, 16\% PFPE, 80\% BADGE/TETA; 9\% n-Al, 21\% PFPE, 70\% BADGE/TETA; and 16\% n-Al, 24\% PFPE, 60\% BADGE/TETA, respectively. After addition of the n-Al/PFPE, the entire mixture is stirred manually with a spatula for $1 \mathrm{~min}$ to ensure a homogenous distribution of the blend into the composite. The BADGE/TETA/n-Al/PFPE mixture is then allowed to fully cure in open air at room temperature for 16$24 \mathrm{~h}$ producing a dark grey, rigid solid.

\section{Results and discussion}

\section{Thermal studies of n-Al/PFPE blends}

The design of a moldable/machinable energetic composite formulation with tailorable energy output led to the selection of Fomblin ${ }^{\circledR}$ Y (a commercially available PFPE). This semiviscous, fluorine-rich fluid serves as a suitable oxidizer coating for high surface area nanometer-sized aluminum (average particle size distribution of $80 \mathrm{~nm}$ with a $2-5 \mathrm{~nm}$ aluminum oxide coating) when thermally activated. Initial studies in order to quantify and optimize the accelerated decomposition of PFPE in the presence of various weight percent n-Al for subsequent incorporation into an epoxy matrix were performed using DSC analysis. The PFPE-coated n-Al resulted in suspensions of clay-like pastes with increased Al loadings from 10-40 wt\%. Selected thermal properties from various weight percent n-Al coated PFPE after being heated to $500{ }^{\circ} \mathrm{C}$ are summarized in Table 1. The DSC trace of PFPE without n-Al showed an exothermic event at $458{ }^{\circ} \mathrm{C}$ which correlates with thermal degradation of PFPE. ${ }^{21}$ Blending PFPE with increased n-Al loadings of $0 \mathrm{wt} \%$ to $40 \mathrm{wt} \%$ drastically accelerated the primary decomposition temperature at maximum $\left(T_{\mathbf{M} 2}\right)$ consecutively from $458{ }^{\circ} \mathrm{C}$ to $310^{\circ} \mathrm{C}$. Sianesi et al. postulated chain scission of the PFPEs whereby a Lewis acid such as $\mathrm{AlCl}_{3}$ coordinates to the perfluoropolyether backbone resulting in the formation of acyl fluoride and the more thermodynamically favorable species $\mathrm{AlF}_{3} .{ }^{22}$

To better quantitate decomposition of n-Al/PFPE blends, the effect of n-Al loading decomposition temperature was calculated relative to PFPE without metal loading by reporting their difference $\left(\Delta T_{\mathrm{M} 2}\right)$. The largest $\Delta T_{\mathrm{M} 2}\left(148^{\circ} \mathrm{C}\right)$ was observed when 
Table 1 Summary of DSC and TGA data of $n$-Al and PFPE mixtures

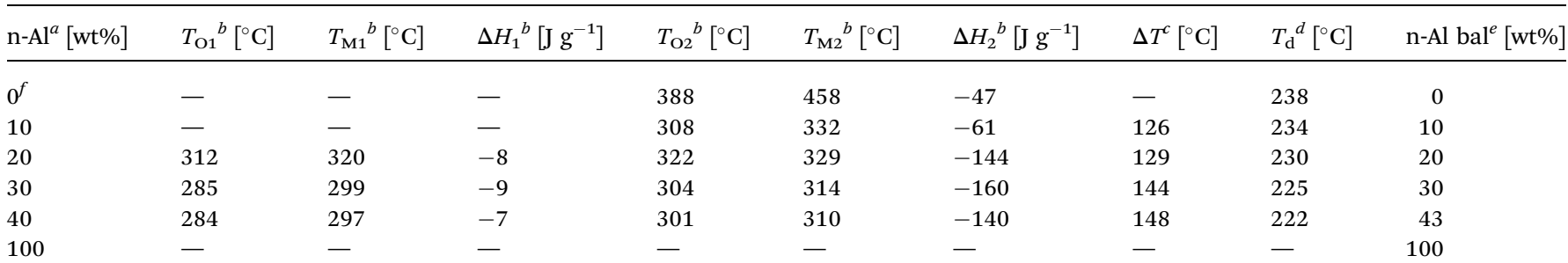

${ }^{a}$ wt $\%$ n-Al blended with PFPE. ${ }^{b}$ DSC $\left(5{ }^{\circ} \mathrm{C} \mathrm{min}{ }^{-1}\right)$ in nitrogen determined by third heating cycle. ${ }^{c}$ Difference of decomposition onset relative to PFPE without n-Al. ${ }^{d}$ TGA onset $\left(5^{\circ} \mathrm{C} \mathrm{min}^{-1}\right)$ in nitrogen. ${ }^{e}$ Residual n-Al balance recorded after $500{ }^{\circ} \mathrm{C}$ using TGA in nitrogen. ${ }^{f}$ PFPE only.

the sample is loaded with $40 \mathrm{wt} \% \mathrm{n}$-Al. In general, the primary onset temperatures $\left(T_{\mathrm{O} 2}\right)$ for decomposition follow a similar trend decreasing significantly (an average of $80{ }^{\circ} \mathrm{C}$ ) even with low loadings of $10 \mathrm{wt} \% \mathrm{n}$-Al. A subtle, yet distinct exothermic event occurs before the primary decomposition exotherm, recorded as $T_{\mathrm{M} 1}$ with onset $T_{\mathrm{O} 1}$. This initial exotherm is detected in the samples loaded with $20-40 \mathrm{wt} \% \mathrm{n}-\mathrm{Al}$. Pantoya and others observed similar exothermic behavior in $\mathrm{n}-\mathrm{Al} /$ Teflon ${ }^{\circledR}$ reactions and referred to this first exotherm as the pre-ignition reaction (PIR). ${ }^{28}$ The PIR presumably attributed to the energy release of a metastable species from the reaction of the fluorocarbon and that of the $\mathrm{Al} / \mathrm{Al}_{2} \mathrm{O}_{3}$ surface via a Grignard-like mechanism, as has been proposed for similar PIR reactions of MTV.,29 Under current experimental reaction conditions, it is not possible to distinguish between Grignard-like insertions of the fluorocarbon on the oxide surface versus insertion into the aluminum core fuel. As observed with the largest exothermic events $\left(T_{\mathrm{O} 2}\right.$ and $\left.T_{\mathrm{M} 2}\right)$, the initial PIR exothermic events $\left(T_{\mathrm{O} 1}\right.$ and $\left.T_{\mathrm{M} 1}\right)$ also tend to decrease to lower temperatures upon increased n-Al weight loading. However, for the $10 \mathrm{wt} \% \mathrm{n}$-Al blend, $T_{\mathrm{M} 2}$ is a broad peak and $T_{\mathrm{M} 1}$ is barely distinguishable and is embedded in the shoulder of the broad exotherm. Loadings of n-Al greater than $40 \mathrm{wt} \%$ were investigated, but produced no increase in $T_{\mathrm{O} 2}$ and $\Delta T_{\mathrm{M} 2}$. In addition, $\mathrm{n}-\mathrm{Al}$ loadings beyond $40 \mathrm{wt} \%$ failed to suppresses further passivation from oxidation to air. The n-Al powder formulation up to $40 \mathrm{wt} \%$ coated with PFPE remained active after six months exposure to open air. Activity is confirmed by thermal DSC analysis and by a propane flame. n-Al coated with PFPE versus uncoated n-Al both instantaneously ignited using a propane flame when immediately removed from the glove box (within ca. $5 \mathrm{~min}$ ). In another qualitative openflame burn test, both uncoated and PFPE coated n-Al were exposed to ambient air for six months. The uncoated n-Al no longer sparked when exposed to an open-flame while the PFPE coated n-Al ignited instantaneously. Enthalpies of reaction $(\Delta H)$ were determined for both the PIR $\left(T_{\mathrm{M} 1}\right)$ and the primary $\left(T_{\mathrm{M} 2}\right)$ exothermic events by integrating the area of the exothermic peak. The integrated areas are listed under the $\Delta H$ column in Table 1. The enthalpies for the primary exothermic event of the $\mathrm{n}$-Al oxidation to $\mathrm{AlF}_{n}$ species in the presence of PFPE are much larger than the enthalpies of the PFPE without metal fuel. The largest $\Delta H$ of $-160 \mathrm{~J} \mathrm{~g}^{-1}$ was repeatedly measured for the major exotherm of the $30 \mathrm{wt} \% \mathrm{n}-\mathrm{Al} / \mathrm{PFPE}$ sample and appears to be the experimental stoichiometric balance of the oxidizer-fuel mixture of this particular system.
Onset of decomposition temperatures $\left(T_{\mathrm{d}}\right)$ by TGA for $\mathrm{n}-\mathrm{Al} /$ PFPE blended samples showed that as the $\mathrm{n}-\mathrm{Al} \mathrm{wt} \%$ loading with the PFPE is increased, the decomposition temperature of the sample decreases as much as $16^{\circ} \mathrm{C}$ with $40 \mathrm{wt} \% \mathrm{n}$-Al loading in nitrogen. There is no char yield up to $500{ }^{\circ} \mathrm{C}$ for only PFPE as these systems quantitatively decompose to traceless, gaseous species. ${ }^{21}$ The remaining measured mass balance is due to $\mathrm{Al}$ and coincides with the prepared blended formulations.

\section{Computational studies of n-Al/PFPE blends}

In order to better understand the energetics of n-Al/PFPE interactions, $a b$ initio calculations were performed to probe the interactions between model perfluoroether molecules and aluminum atoms. Specifically, the Gaussian suite of programs ${ }^{\mathbf{3 0}}$ was employed in order to probe the strengths of the interactions of $\mathrm{Al}$ atoms and $\mathrm{CF}_{3} \mathrm{OCF}_{3}$ or $\mathrm{CF}_{3} \mathrm{CF}_{2} \mathrm{OCF}_{3}$ in various orientations. Subsequently, a fluorine atom was removed from the perfluoroether molecule, bonded to the $\mathrm{Al}$ atom, and the two fragments were then re-optimized. Finally, attempts to find transition states between the Al-ether complex and the AlFether fragment complex were performed. The relative energies of the complex, transition state, and fragments were compared in order to understand the energy barrier to $\mathrm{F}$ atom transfer, which is thought to be the initial step in the reaction between $\mathrm{Al}$ and perfluoroether. Hartree-Fock (HF) calculations using the standard 6-31G(d,p) basis set ${ }^{31}$ were employed, with a multiplicity of 2 for all systems.

Results of the HF/6-31G(d,p) calculations showed that the interaction energies of the $\mathrm{Al}$ atom with the model perfluoroethers is very low, on the order of $3 \mathrm{~kJ} \mathrm{~mol}^{-1}$ for interacting through an $\mathrm{F}$ atom, and about $8 \mathrm{~kJ} \mathrm{~mol}^{-1}$ for interacting through the O-atom. For the O-bonded perfluorodimethylether$\mathrm{Al}$ complex, transfer of an $\mathrm{F}$ atom to the $\mathrm{Al}$ led to a decrease in energy of approximately $115 \mathrm{~kJ} \mathrm{~mol}^{-1}$, as shown in Fig. 1 (left). For this complex, the transition state for the $\mathrm{F}$ transfer to $\mathrm{Al}$ was found to be $151 \mathrm{~kJ} \mathrm{~mol}^{-1}$ higher in energy than the complex itself. This indicates a reasonably high energy barrier for reaction which is consistent with the experimental need to increase the temperature to initiate decomposition. Similar calculations for the perfluoromethylethylether-Al complex yielded similar results (see also Fig. 1) between reactants and products. The amount of energy decrease for $\mathrm{F}$ atom transfer varied depending on the source of the F atom. Fig. 1 (right) shows an example where the point of extraction is the methylene carbon of the 

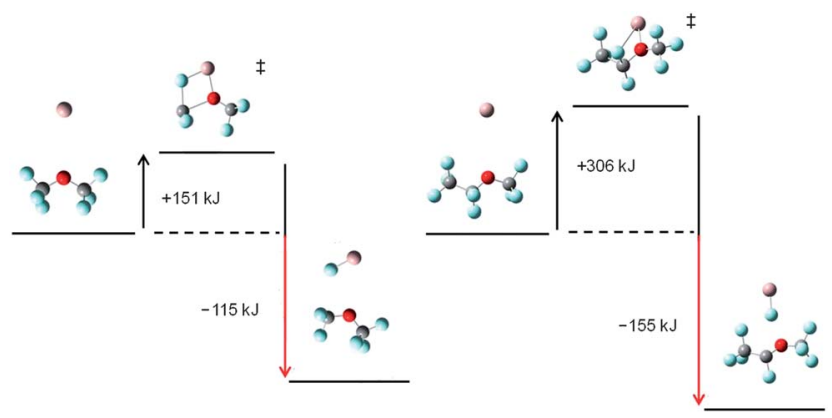

Fig. 1 Reaction profiles for the abstraction by an $\mathrm{Al}$ atom of a $\mathrm{F}$ atom from perfluorodimethylether (left) and perfluoromethylethylether (right). Key: $\ddagger=$ transition state; aqua $=$ fluorine; dark red $=$ oxygen; grey $=$ carbon; light red $=$ aluminum.

ether's ethyl group. When the $\mathrm{F}$ atom is abstracted from the methyl carbon of the ethyl group, the identified transition state was $306 \mathrm{~kJ} \mathrm{~mol}^{-1}$ higher in energy than the Al-ether complex. Upon $\mathrm{F}$ atom transfer, the overall energy change is $-155 \mathrm{~kJ}$ $\mathrm{mol}^{-1}$. Further calculations showed that when the $\mathrm{F}$ atom is abstracted from the methyl group on the other side, the net energy change is somewhat less at $-124 \mathrm{~kJ} \mathrm{~mol}^{-1}$. All of these calculations support the fact that the initial steps of the formation of aluminum fluoride species (ultimately, $\mathrm{AlF}_{3}$ ) is decidedly exothermic.

\section{Energetic composite fabrication and thermal characterization}

After the n-Al/PFPE blends were optimized for energy output based on thermal activation from DSC analysis, the formulations are incorporated into an epoxy-based matrix. The epoxy matrix selected for this study included common monomers, diethylenetrimine (DETA) and bisphenol A diglycidyl ether (BADGE), in an optimized ratio of $1: 4 \mathrm{wt} \%$, cured at room temperature with no catalyst. The selection of this epoxy matrix was intentional because it is a thermally stable matrix up to $325{ }^{\circ} \mathrm{C}$ under nitrogen; therefore, the n-Al/PFPE oxidationreduction event could be observed using DSC analysis (vida supra). Phase separation of $\mathrm{n}-\mathrm{Al} / \mathrm{PFPE}$ in the epoxy matrix was mitigated by introducing the blend during the partial pre-stage cure after $2 \mathrm{~h}$ followed by a final thermoset cure producing a rigid, homogeneous material after $16 \mathrm{~h}$. Prolonged exposure $(24 \mathrm{~h})$ of the fully cured metallized composites to various nonpolar/polar solvents (hexanes, acetone, methanol, chloroform, and dimethylformamide) at their boiling point failed to swell the network material or produce evidence of n-Al or PFPE leaching. Because of the ability to partially cure forming a viscous, yet free-flowing material, the n-Al/PFPE blended epoxy composites can be molded into functional shapes and machined post-cure. For comparison of thermal studies, control composites are also prepared by adding n-Al or PFPE exclusively to the DETA/BADGE epoxy matrix. Fig. 2 illustrates photos of cured, unblended DETA/BADGE epoxide, epoxy loaded with PFPE only (top from left to right, respectively), composite loaded with n-Al/PFPE blend, and the same metalized, blended composite post-machined (bottom from left to right, respectively). Machining of these components was

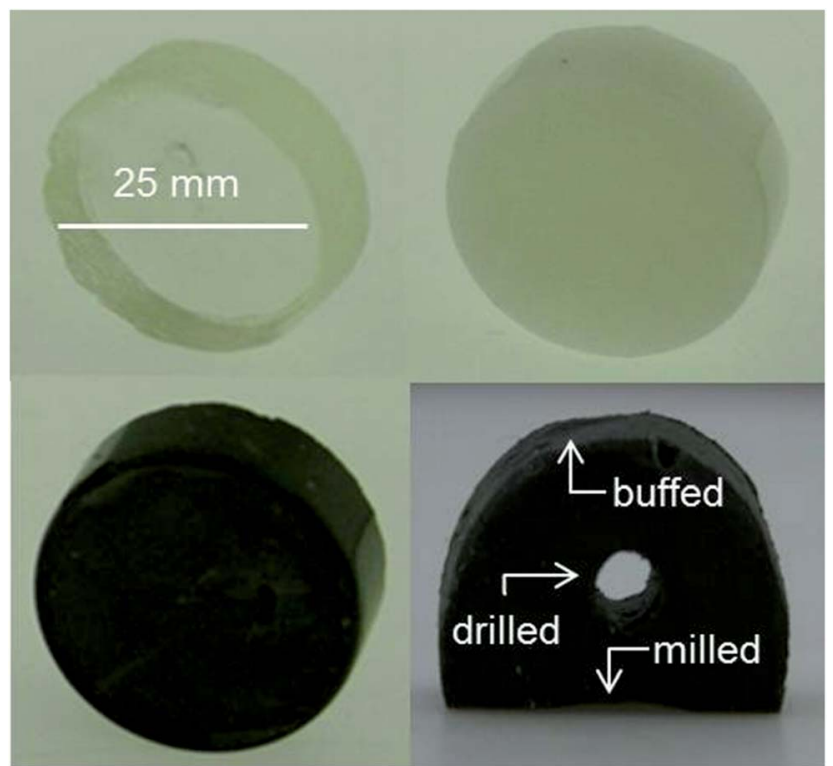

Fig. 2 Pictures of the composites. Top: (left) cured epoxy (control), (right) epoxy loaded with 20 wt\% PFPE only; bottom: (left) epoxy composite loaded with 9 wt $\% \mathrm{n}$-Al and 21 wt\% PFPE, (right) epoxy composite after machining (drilled out core, buffed edges and mill cut on bottom).

achieved with no observation of ignition due to mechanical shearing induced by buffing, milling, or drilling. Attempts to prepare n-Al filled DETA/BADGE (no PFPE, figure not shown) failed to produce a fully cured material at room temperature or vacuum oven at room temperature or elevated temperatures. This n-Al loaded epoxy composite had significant voids and noticeable metal aggregate as observed by TEM microscopy analysis (vida infra). In fact, the maximum amount of $\mathrm{n}-\mathrm{Al}$ particles that can be incorporated into the composite matrix before the material could not cure was only $5 \mathrm{wt} \%$. In contrast, when the n-Al/PFPE blends were added to the composite, the particles appeared to be easily distributed into the composite and the resulting materials cured uniformly and without phase separation. The maximum amount of PFPE that can be loaded into the composite and still form a rigid material was $30 \mathrm{wt} \%$; loadings greater than $30 \mathrm{wt} \%$ caused the material not to fully cure even after extended reaction time and elevated temperature. Loading up to $40 \mathrm{wt} \%$ of the n-Al/PFPE blend was the upper limit in order to yield a desirable cured, homogeneous material.

Thermal analysis employing DSC and TGA measurements of the epoxy composites loaded with n-Al/PFPE blends is summarized in Table 2. Heating the cured epoxy composite samples loaded with the n-Al/PFPE blends produced similar primary exothermic activation temperature $T_{\mathrm{O}}$ and $T_{\mathrm{M}}$ to that of the epoxy control with no evidence of the PIR temperature. DSC thermograms show that the $\Delta H$ of the composites is very similar to those of the blends. Because the heat capacities are relatively the same for both the blends and the composite, it is presumed that the composite matrix does not perturb the exothermic outcome of the reaction and therefore is a suitable host structural material.

Fig. 3 shows representative DSC plots in the region of the exothermic event of the pure PFPE, a n-Al/PFPE blend, and two 
Table 2 Summary of DSC and TGA data of epoxy composites loaded with n-Al and PFPE

\begin{tabular}{|c|c|c|c|c|c|c|c|c|}
\hline Epoxy [wt\%] & $\mathrm{n}-\mathrm{Al}[\mathrm{wt} \%]$ & PFPE [wt\%] & $T_{\mathrm{g}}{ }^{a}\left[{ }^{\circ} \mathrm{C}\right]$ & $T_{\mathrm{O}}{ }^{a}\left[{ }^{\circ} \mathrm{C}\right]$ & $T_{\mathrm{M}}{ }^{a}\left[{ }^{\circ} \mathrm{C}\right]$ & $\Delta H^{a}\left[\mathrm{~J} \mathrm{~g}^{-1}\right]$ & $T_{\mathrm{d}}^{b}\left[{ }^{\circ} \mathrm{C}\right]$ & $\mathrm{n}-\mathrm{Al} \mathrm{bal}^{c}[\mathrm{wt} \%]$ \\
\hline 100 & 0 & 0 & 79 & 310 & 335 & -48 & 325 & $5^{d}$ \\
\hline 80 & 0 & 20 & 67 & 314 & 340 & -77 & 322 & 4 \\
\hline 90 & 1 & 9 & 77 & 304 & 337 & -140 & 327 & 7 \\
\hline 80 & 4 & 16 & 77 & 305 & 340 & -141 & 328 & 10 \\
\hline 70 & 9 & 21 & 77 & 298 & 339 & -128 & 328 & 14 \\
\hline
\end{tabular}

${ }^{a}$ DSC $\left(5{ }^{\circ} \mathrm{C} \mathrm{min}{ }^{-1}\right)$ in nitrogen determined by third heating cycle. ${ }^{b}$ TGA onset $\left(5{ }^{\circ} \mathrm{C} \mathrm{min}{ }^{-1}\right)$ in nitrogen. ${ }^{c}$ Residual n-Al recorded after $500{ }^{\circ} \mathrm{C}$ using TGA in nitrogen. ${ }^{d}$ For control epoxy resin, no n-Al and/or PFPE, $5 \mathrm{wt} \%$ carbon char was observed at $900{ }^{\circ} \mathrm{C}$.

separate composites: one loaded with PFPE only and the other loaded with the $\mathrm{n}-\mathrm{Al} / \mathrm{PFPE}$ blend. As previously discussed, the PFPE does not decompose until $458{ }^{\circ} \mathrm{C}$ according to DSC, but this decomposition is accelerated in the presence of the n-Al. The plot of the $10 \mathrm{wt} \% \mathrm{n}$-Al blended with PFPE (black plot) clearly displays an exothermic transition peak maximum at $332{ }^{\circ} \mathrm{C}$ whose integrated area yields a $\Delta H$ of $-61 \mathrm{~J} \mathrm{~g}^{-1}$ (see also entry in Table 1). When the maximum loading of $16 \mathrm{wt} \% \mathrm{n}-\mathrm{Al}$ PFPE blended composite is measured (blue plot), the integrated heat capacity yields $-112 \mathrm{~J} \mathrm{~g}^{-1}$. However, lower loadings of $1 \mathrm{wt}$ $\%$ and $5 \mathrm{wt} \% \mathrm{n}$-Al PFPE blended composite are only required to achieve maximum energy output of $-140 \mathrm{~J} \mathrm{~g}^{-1}$, nearly three-fold increase over the unfilled cured epoxy matrix $\left(-48 \mathrm{~J} \mathrm{~g}^{-1}\right)$. Clearly, the energetic reaction between the n-Al and the PFPE occurs just as efficiently when the blend is incorporated into the composite host matrix. This observation is further confirmed by only slight broadening of the exotherm when comparing the $\mathrm{n}$ $\mathrm{Al} / \mathrm{PFPE}$ blend and the blend loaded in the composite (compare black and blue plot, Fig. 3). Beyond $325{ }^{\circ} \mathrm{C}$, it is apparent the epoxy matrix begins to degrade by an overlapping, yet discrete exotherm; this is confirmed with subsequent TGA analysis.

The idea of the cured epoxy serving as a non-perturbing host under thermal stress is further supported by the reported glass transition temperatures $\left(T_{\mathrm{g}}\right)$ of the composites listed in Table 2

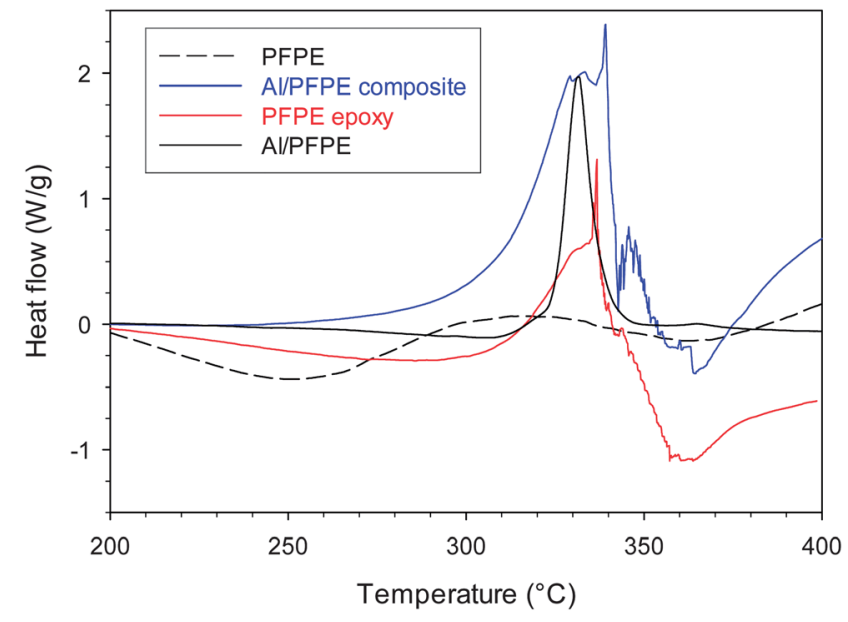

Fig. 3 DSC plots of PFPE (black dashes), 10 wt $\%$ n-Al PFPE blend (black), 5 wt $\%$ PFPE epoxy (red), and 16 wt\% n-Al PFPE blend epoxy composite (blue). Y-axis plotted as exotherm up.

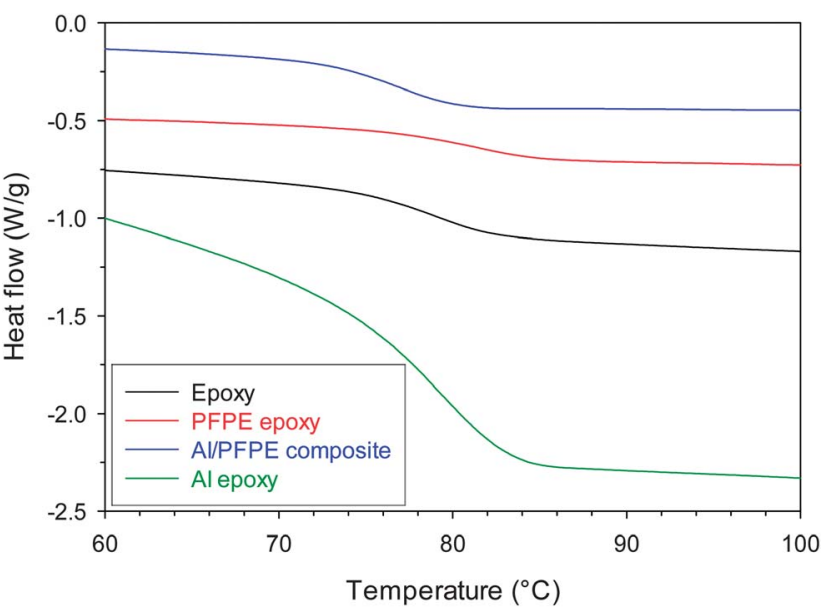

Fig. 4 Glass transition temperatures $\left(T_{\mathrm{g}}\right)$ of the cured epoxy network without any additive (black), loaded with 5 wt $\%$ PFPE (red), loaded with 5 wt $\%$ n-Al (green), and $1 \mathrm{wt} \% \mathrm{n}$-Al/PFPE blend (blue). $Y$-axis plotted as exotherm up.

and illustrated in Fig. 4. The $T_{\mathrm{g}}$ of the epoxy network (black plot) does not change after the epoxy composite is cured with the PFPE (red plot), n-Al (green plot), or the n-Al/PFPE blend (blue plot). Therefore, the structural integrity of the material is maintained regardless of the additive composition except for the formulation of n-Al only epoxy composite (green plot). The broader, steeper $T_{\mathrm{g}}$ is presumably due to bulk agglomeration of $\mathrm{n}$-Al creating large void volumes in the bulk material and localized heat transfer to the aggregated metal.

The onset decomposition temperatures $\left(T_{\mathrm{d}}\right)$ and mass balances were measured with TGA and listed in Table 2. Fig. 5 shows the selected thermograms as recorded by TGA of a cured control epoxy (black plot), the PFPE (green plot), epoxy loaded with $20 \mathrm{wt} \%$ PFPE (red plot), and the epoxy composite loaded with a blend of $1 \mathrm{wt} \% \mathrm{n}-\mathrm{Al}$ and $9 \mathrm{wt} \%$ PFPE. Unlike the PFPE, the cured epoxy has a low carbon char yield of $5 \mathrm{wt} \%$ at $900{ }^{\circ} \mathrm{C}$. When loaded with n-Al/PFPE blends, the remaining mass balances (less carbon char yield) are consistently proportional to the amount of n-Al. Furthermore, when only PFPE is loaded into the cured epoxy matrix, this formulation decomposes gradually at onset more readily than the cured epoxy control without expected stepwise degradation. However, it is interesting to note that when loaded with the $1 \mathrm{wt} \% \mathrm{n}-\mathrm{Al} / \mathrm{PFPE}$ blend, the epoxy composite decomposes at the same temperature as 


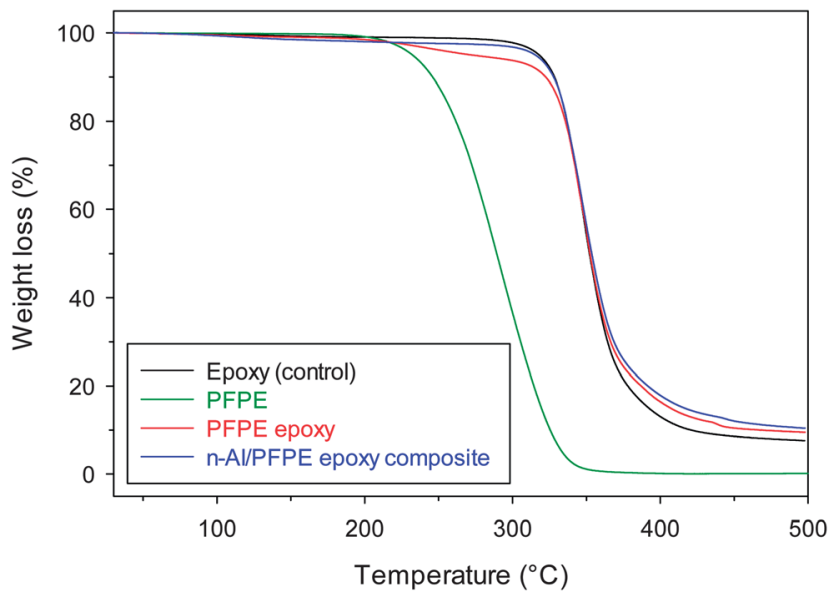

Fig. 5 TGA of the control epoxide without any dopants (black), PFPE (green), an epoxide loaded with $20 \mathrm{wt} \%$ PFPE (red) and an epoxide composite loaded with a $1 \mathrm{wt} \%$ n-Al PFPE (blue).

the pure epoxide control. Because metals are better thermal conductors than organic polymers, it is assumed external heat transfers to the dispersed n-Al first inducing PFPE chain scission, followed by heat dissipation to the epoxy matrix ultimately facilitating thermal degradation.

\section{Microscopy analysis of energetic composites and post-burn analysis}

The surface topographies of various samples were examined initially by SEM. The images of $n$-Al particles and a blend of particles with PFPE are shown in Fig. 6. The n-Al particles appear to aggregate uniformly in $c a .5 \mu \mathrm{m}$ domains. The image of the particles blended with PFPE appears to be less sharp and slightly less focused than the n-Al particles themselves; this is likely due to the PFPE that coats the particles uniformly. The aggregation of nanoparticles also appears to be less noticeable when the n-Al particles are coated with the PFPE. SEM images of the cured epoxy composites were difficult to obtain because the samples burn even at low accelerating voltages.

TEM analysis was used to obtain higher resolution images of the prepared samples. TEM images of the same $\mathrm{n}-\mathrm{Al}$ and the blend sample pictured in Fig. 6 are shown in Fig. 7(a) and (b), respectively. Additionally, the epoxy composite loaded with a blend of $16 \mathrm{wt} \% \mathrm{n}-\mathrm{Al}$ with PFPE is shown in Fig. 7(c) and a $5 \mathrm{wt} \%$ epoxy composite loaded with n-Al particles (no PFPE) is pictured in (d). At higher resolution, the pure n-Al and the PFPE coated nAl particles look very similar consistent with SEM analysis. The

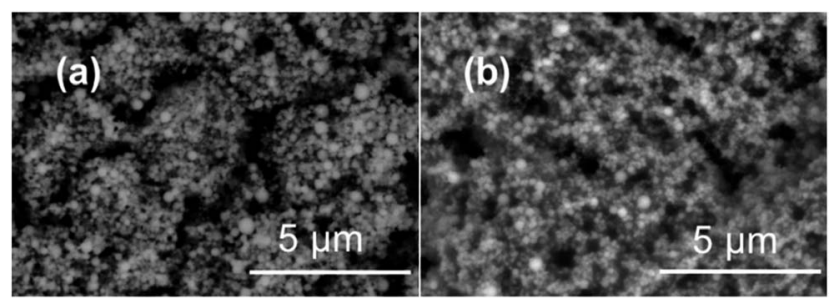

Fig. 6 SEM images of (a) n-Al and (b) a blend of 30 wt $\%$ n-Al/PFPE blend.

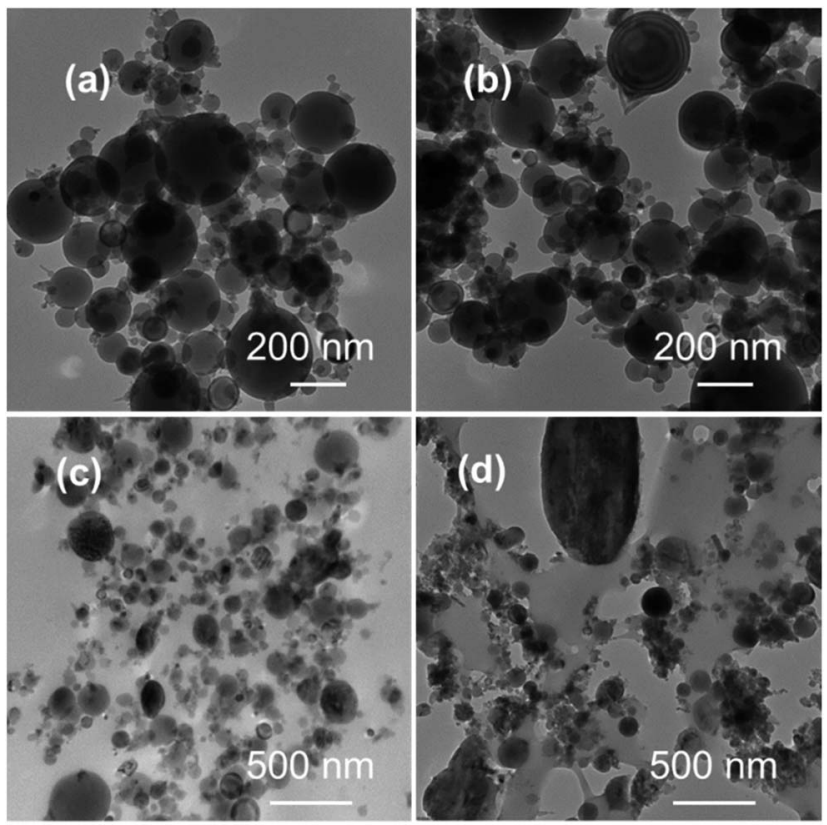

Fig. 7 TEM images of (a) n-Al nanoparticles, (b) $30 w t \% n-A l / P F P E$ blend, (c) 16 $w t \% n$-Al/PFPE epoxy composite and (d) epoxy loaded with $5 \mathrm{wt} \% \mathrm{n}$-Al (no PFPE).

$16 \mathrm{wt} \% \mathrm{n}-\mathrm{Al} / \mathrm{PFPE}$ blend show excellent dispersion into the epoxy matrix as shown in Fig. 7(c). On the other hand, when only $5 \mathrm{wt} \% \mathrm{n}-\mathrm{Al}$ is prepared in the cured epoxy, the micrograph (d) show the particles are poorly distributed in the matrix resulting in a material consistent with voids. As previously noted, the composite prepared with only n-Al particles was prone to poor, inconsistent curing.

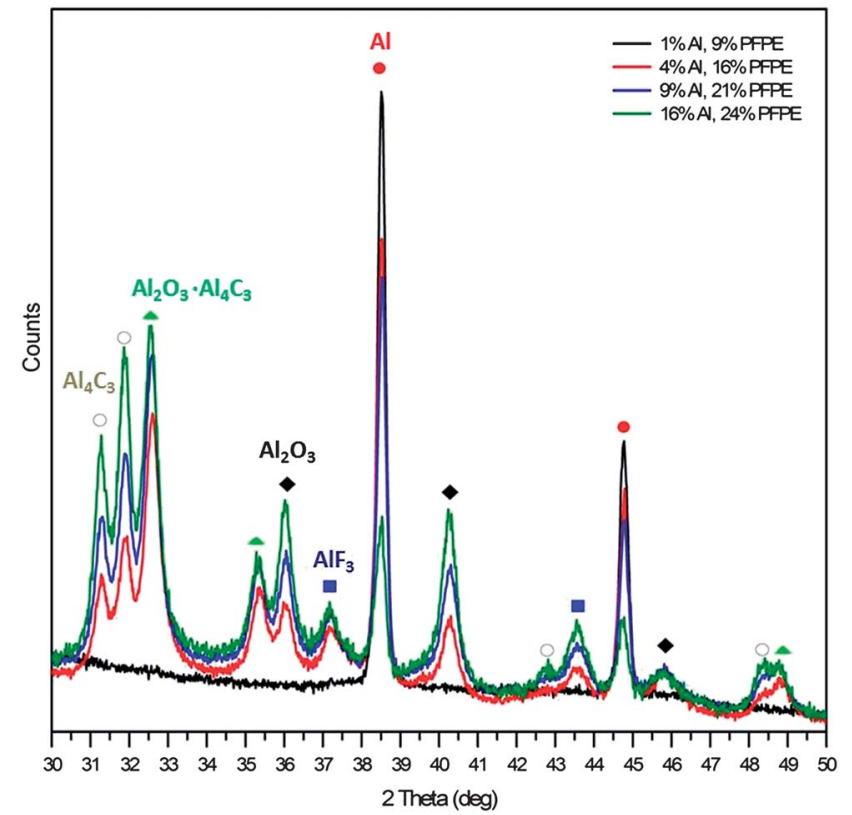

Fig. 8 Post-burn XRD analysis of four different composite samples loaded with 1 wt $\%$ n-Al, 9 wt\% PFPE (black); 4 wt $\%$ n-Al, 16 wt $\%$ PFPE (red); 9 wt $\%$ n-Al, 21 wt $\%$ PFPE (blue) and 16 wt $\%$ n-Al, 24 wt $\%$ PFPE (green). Circle (red) = Al; square $($ blue $)=\mathrm{AlF}_{3}$; diamond $($ black $)=\mathrm{Al}_{2} \mathrm{O}_{3}$; open circle $($ black $)=\mathrm{Al}_{4} \mathrm{C}_{3}$; triangle (green) $=\mathrm{Al}_{2} \mathrm{O}_{3} \cdot \mathrm{Al}_{4} \mathrm{C}_{3}$. 
Qualitative open air burn tests were performed on all n-Al/ PFPE loaded epoxy samples using a propane torch. When exposed to the flame, the composites initially sparked and subsequently readily ignited with a sustained burn to afford a charred grey powder. Powder X-ray diffraction (XRD) was performed on all charred samples and their corresponding traces are shown in Fig. 8. As the n-Al/PFPE loadings are increased from $1 \mathrm{wt} \% \mathrm{n}-\mathrm{Al} / 9 \mathrm{wt} \%$ PFPE to $16 \mathrm{wt} \% \mathrm{n}-\mathrm{Al} / 24 \mathrm{wt} \%$ PFPE, the signals for $\mathrm{AlF}_{3}, \mathrm{Al}_{2} \mathrm{O}_{3}$, and $\mathrm{Al}_{4} \mathrm{C}_{3}$ proportionally increased while the signal for $\mathrm{Al}$ decreases. In fuel (n-Al) poor, oxidizer (PFPE) rich samples, there is not enough $\mathrm{n}-\mathrm{Al}$ available for reaction as demonstrated for the $1 \mathrm{wt} \% \mathrm{n}$-Al sample. Conversely, as the concentration of $\mathrm{n}-\mathrm{Al}$ is increased, there is sufficient fuel present for fluorination, oxygenation, and carburation reactions to occur as shown for n-Al loadings $4 \mathrm{wt} \%$ or above.

\section{Conclusion}

This work reports the first preparation of an epoxy-based composite entrained with a metastable PFPE coated n-Al powder formulation reactive upon thermal ignition. The ability to partially cure this system enables the fabrication of moldable components that ultimately cure with no net dimensional change (shrinkage) at room temperature and do not require the use of a catalyst. Parts can also be machined post-cure. SEM and TEM indicated excellent dispersion of the PFPE coated $\mathrm{n}-\mathrm{Al}$ as a blend in the epoxy matrix that could not be achieved with n-Al loading alone. The glass transition temperatures remain unchanged with increased loadings of $n-\mathrm{Al} / \mathrm{PFPE}$ in the epoxy network which demonstrate the morphology of the n-Al domains remain unperturbed until activation. Thermal analysis using DSC and TGA confirmed the metal-mediated degradation of PFPE leading to oxidation of $\mathrm{n}-\mathrm{Al}$ and quantified the energy output in order to determine the experimental stoichiometric balance of the fuel-oxidizer formulation. Post-burn XRD analysis of open-air ignited composite samples further validated the formation of predominant metal oxidized species $\mathrm{AlF}_{3}, \mathrm{Al}_{2} \mathrm{O}_{3}$, and $\mathrm{Al}_{4} \mathrm{C}_{3}$.

Given the simplistic fabrication of this epoxy-based metal/ fluoropolymer energetic composite system, other formulations with various metals, network polymers, and PFPEs warrant consideration. The epoxy matrix was not only successful in encapsulating/stabilizing $\mathrm{n}$-Al oxidizer and PFPE fuel blend until thermal activation, this pre-mixed combination was required to fully cure the system creating a well-dispersed, homogeneous composite. PFPEs (available with varying molecular weight and functional end-groups) have been known to undergo accelerated decomposition in the presence of other metals and also metal oxides. The combination of such oxidizer/fuel combinations in order to achieve optimum stoichiometric balanced energy output remains a part of our ongoing investigations.

\section{Acknowledgements}

The authors would like to acknowledge and thank Dr JoAn Hudson and George Wetzel (Clemson University Electron
Microscopy Facility) for the SEM and TEM images. SCK acknowledges funding for this work made available by Air Force Research Laboratory, Eglin Air Force Base, sponsored by the US Air Force Academy under agreement number FA7000-10-2-0038.

\section{References}

1 E.-C. Koch, Metal-Fluorocarbon Based Energetic Materials, Wiley-VCH Verlag GmbH \& Co. KGaA, Germany, 2012.

2 E.-C. Koch, in Handbook of Combustion, ed. M. Lackner, F. Winter and A. K. Agarwal, Wiley-VCH Verlag GmbH \& Co. KGaA, 2010, pp. 355-402.

3 E. A. Cadwallader, Flare Composition, US Pat., 3,152,935, 1964.

4 R. E. Colvin, B. E. Douda, F. E. Montgomery and J. E. Short, Jr, Disposing of decoy flare material, US Pat. , 4,276,100, 1981.

5 C. A. Knapp, New Infrared Flare and High-Altitude Igniter Compositions, ed. N. J. Dover, Feltman Research and Engineering Laboratories, P. A., 1959, p. 21.

6 I. Lee, R. R. Reed, V. L. Brady and S. A. Finnegan, J. Therm. Anal., 1997, 49, 1699-1705.

7 H.-L. Lin, S.-H. Yeh, T. L. Yu and L.-C. Chen, J. Polym. Res., 2009, 16, 519-527.

8 M. L. Pantoya and S. W. Dean, Thermochim. Acta, 2009, 493, 109-110.

9 A. Gash, N. N. Thadhani, W. H. Wilson, R. W. Armstrong and Z. A. Munir, in Materials Research Society Symposium, Boston, MA, 2005, pp. 130-132.

10 E. M. Hunt, S. Malcolm, M. L. Pantoya and F. Davis, Int. J. Impact Eng., 2009, 36, 842-846.

11 K. W. Watson, M. L. Pantoya and V. I. Levitas, Combust. Flame, 2008, 155, 619-634.

12 V. I. Levitas, B. W. Asay, S. F. Son and M. Pantoya, J. Appl. Phys., 2007, 101, 083524.

13 C. A. Crouse, C. J. Pierce and J. E. Spowart, ACS Appl. Mater. Interfaces, 2010, 2, 2560-2569.

14 J. J. Brege, C. E. Hamilton, C. A. Crouse and A. R. Barron, Nano Lett., 2009, 9, 2239-2242.

15 W. K. Lewis, A. T. Rosenberger, J. R. Gord, C. A. Crouse, B. A. Harruff, K. A. S. Fernando, M. J. Smith, D. K. Phelps, J. E. Spowart, E. A. Guliants and C. E. Bunker, J. Phys. Chem. C, 2010, 114, 6377-6380.

16 C. A. Crouse, C. J. Pierce and J. E. Spowart, Combust. Flame, 2012, 159, 3199-3207.

17 S. Yan, G. Jian and M. R. Zachariah, ACS Appl. Mater. Interfaces, 2012, 4, 6432-6435.

18 Y.-S. Kwon, G. A. Gromov and J. I. Strokova, Appl. Surf. Sci., 2007, 253, 5558-5564.

19 B. Dikici, S. W. Dean, M. L. Pantoya, V. I. Levitas and R. J. Jouet, Energy Fuels, 2009, 23, 4231-4235.

20 D. A. Yagodnikov, E. A. Andreev, V. S. Vorob'ev and O. G. Glotov, Combust., Explos. Shock Waves, 2006, 42, 534542.

21 J. Scheirs, in Modern Fluoropolymers, ed. J. Scheirs, John Wiley \& Sons Ltd, 1997, p. 637.

22 D. Sianesi, A. Pasetti and C. Corti, Macromol. Chem., 1965, 86, 308-311. 
23 P. Herrera-Fierro, S. V. Pepper and W. R. Jones, J. Vac. Sci. Technol., A, 1992, 10, 2746-2751.

24 P. Herrera-Fierro, W. R. Jones and S. V. Pepper, J. Vac. Sci. Technol., A, 1993, 11, 354-367.

25 D. W. Ball, High Temp. Mater. Sci., 1995, 33, 171-190.

26 P. H. Kasai, Macromolecules, 1992, 25, 6791-6799.

27 K. B. Rider, B. K. Little, S. B. Emery and C. M. Lindsay, Propellants, Explos., Pyrotech., 2012, DOI: 10.1002/ prep.201200118.

28 M. L. Pantoya and S. W. Dean, Thermochim. Acta, 2009, 493, 109-110.

29 E.-C. Koch, Propellants, Explos., Pyrotech., 2002, 27, 340-351.

30 M. J. Frisch, G. W. Trucks, H. B. Schlegel, G. E. Scuseria, M. A. Robb, J. R. Cheeseman, J. A. Montgomery, Jr, T. Vreven, K. N. Kudin, J. C. Burant, J. M. Millam, S. S. Iyengar, J. Tomasi, V. Barone, B. Mennucci, M. Cossi, G. Scalmani, N. Rega, G. A. Petersson, H. Nakatsuji, M. Hada, M. Ehara, K. Toyota, R. Fukuda,
J. Hasegawa, M. Ishida, T. Nakajima, Y. Honda, O. Kitao, H. Nakai, M. Klene, X. Li, J. E. Knox, H. P. Hratchian, J. B. Cross, V. Bakken, C. Adamo, J. Jaramillo R. Gomperts, R. E. Stratmann, O. Yazyev, A. J. Austin, R. Cammi, C. Pomelli, J. W. Ochterski, P. Y. Ayala, K. Morokuma, G. A. Voth, P. Salvador, J. J. Dannenberg, V. G. Zakrzewski, S. Dapprich, A. D. Daniels, M. C. Strain, O. Farkas, D. K. Malick, A. D. Rabuck, K. Raghavachari, J. B. Foresman, J. V. Ortiz, Q. Cui, A. G. Baboul, S. Clifford, J. Cioslowski, B. B. Stefanov, G. Liu, A. Liashenko, P. Piskorz, I. Komaromi, R. L. Martin, D. J. Fox, T. Keith, M. A. Al-Laham, C. Y. Peng, A. Nanayakkara, M. Challacombe, P. M. W. Gill, B. Johnson, W. Chen, M. W. Wong, C. Gonzalez and J. A. Pople, Gaussian 03; Revision D.01, Gaussian, Inc., Wallingford CT, 2004.

31 P. C. Hariharan and J. A. Pople, Theor. Chim. Acta, 1973, 28, 213-222. 